\title{
Massive Spontaneous Cervicomediastinal Hemorrhage from a Parathyroid Adenoma
}

\author{
Rajiv V Dave ${ }^{1,2}$, John Ciciulla ${ }^{3}$, Philip Antippa ${ }^{4}$, Julie A Miller ${ }^{2,5}$
}

\begin{abstract}
Aim: We aimed to describe an unusual case of a patient presenting with subacute neck and chest tightness, and eventual ecchymosis, leading to the diagnosis of a bleeding parathyroid adenoma. We summarize the current literature and discuss important learning points.

Background: Significant neck hematoma is a rare condition, and related most frequently to trauma. Rarer causes can include bleeding from the thyroid or parathyroid gland.

Case description: A 62-year-old woman presented with subacute neck and chest tightness, and eventual progressive neck swelling and skin discoloration. Initial radiological investigations could not identify the source of bleeding, and subsequent outpatient investigations included a gastrograffin swallow, endoscopic ultrasound, and positron emission tomography. A follow-up contrast CT scan, a sestamibi scan, and USS characterized a right-sided neck nodule to be a likely parathyroid adenoma, confirmed by a raised parathyroid-hormone level and serum calcium. Minimally invasive parathyroidectomy, four months following initial diagnosis, revealed fused tissue planes, with residual petechial hemorrhage. A $813 \mathrm{mg}$ atypical parathyroid adenoma was resected, with hemosiderin being evident within the gland.

Conclusion: Review of the literature reveals some similarities to the case described herein, with patients of a similar demographic presenting with symptoms of hoarseness, dysphagia, cervical swelling, and ecchymosis. The physiopathological mechanisms behind such nontraumatic bleeding from the parathyroid gland remains unknown.

Clinical significance: A clinical triad of acute neck swelling, hypercalcemia, and neck and/or chest ecchymosis should evoke the potential diagnosis of ruptured parathyroid adenoma. Once the diagnosis is confirmed, minimally invasive parathyroid is a safe approach in experienced hands. Keywords: Endocrine surgery, Neck hematoma, Parathyroid adenoma, Spontaneous hemorrhage.

World Journal of Endocrine Surgery (2019): 10.5005/jp-journals-10002-1263
\end{abstract}

\section{BACKGROUND}

Significant neck hematoma is a rare condition, and most frequently related to trauma, infection, ingestion of foreign body, or iatrogenic injury following angiography. ${ }^{1,2}$ Less commonly, spontaneous neck hematoma may occur as a result of thyroid or parathyroid bleeding in the presence of a thyroid cyst, nodular goiter, subacute thyroiditis, or parathyroid adenoma, hyperplasia, cysts, or carcinoma.

Here, we describe a patient presenting with spontaneous massive cervicomediastinal hemorrhage, eventually diagnosed as a ruptured parathyroid adenoma. Once the hemorrhage settled, she was treated electively using a minimally invasive approach. We discuss the optimum and timing of and approach to surgery.

\section{Case Description}

\section{Clinical Presentation}

A 62-year-old woman, who was previously fit and well, presented to the emergency department of her regional hospital with subacute neck and chest tightness, occurring immediately following breakfast. She was admitted for further investigations, and during her inpatient stay, developed progressive neck swelling and skin discoloration (Figs $1 A$ and B). There were no compressive symptoms such as dyspnea or dysphagia, and she was not systemically unwell. On examination the neck was diffusely swollen with overlying tenderness and an ecchymosis, which worsened over five days, extending to the xiphisternum and across both breasts (Fig. 1C).

A contrast computed tomography (CT) scan of the neck and chest showed a mass/density seen in the neck, extending from the lateral neck to the prevertebral/paratracheal spaces into the thorax,
${ }^{1}$ Department of Oncoplastic Breast and Endocrine Surgery, Nightingale Centre, Manchester University NHS Foundation Trust, Wythenshawe, Manchester, UK

${ }^{2}$ Department of Surgery, Endocrine Surgery unit, Royal Melbourne Hospital, Parkville, Victoria, Australia

${ }^{3}$ Department of Pathology, Melbourne Pathology, Collingwood, Victoria, Australia

${ }^{4}$ Cardiothoracic Surgery Unit, Royal Melbourne Hospital, Parkville, Victoria, Australia

${ }^{5}$ Epworth Freemasons Hospital, East Melbourne, Victoria, Australia

Corresponding Author: Julie A Miller, Department of Surgery, Endocrine Surgery unit, Royal Melbourne Hospital, Parkville, Victoria, Australia; Epworth Freemasons Hospital, East Melbourne, Victoria, Australia, Phone: +61 (03)9342 8212, e-mail: Julie.Miller@mh.org.au

How to cite this article: Dave RV, Ciciulla J, et al. Massive Spontaneous Cervicomediastinal Hemorrhage from a Parathyroid Adenoma. World J Endoc Surg 2019;11(2):64-69.

Source of support: Nil

Conflict of interest: None

with a significant hemothorax. She was transferred to our tertiary hosptial's thoracic surgery unit five days after initial presentation, where she was transfused two units of packed red blood cells for a hemoglobin of $107 \mathrm{~g} / \mathrm{L}$ with normal vital signs. Ultrasound scan (USS) and repeat computed tomography (CT) scans (Fig. 2) were performed, which confirmed the presence of a $60 \times 25 \times 101 \mathrm{~mm}$ mass in the thoracic inlet, adjacent to the oesophagus and vertebral body. A diagnosis of oesophageal cancer was entertained, and a CT-guided biopsy was attempted, but revealed only a hematoma. 


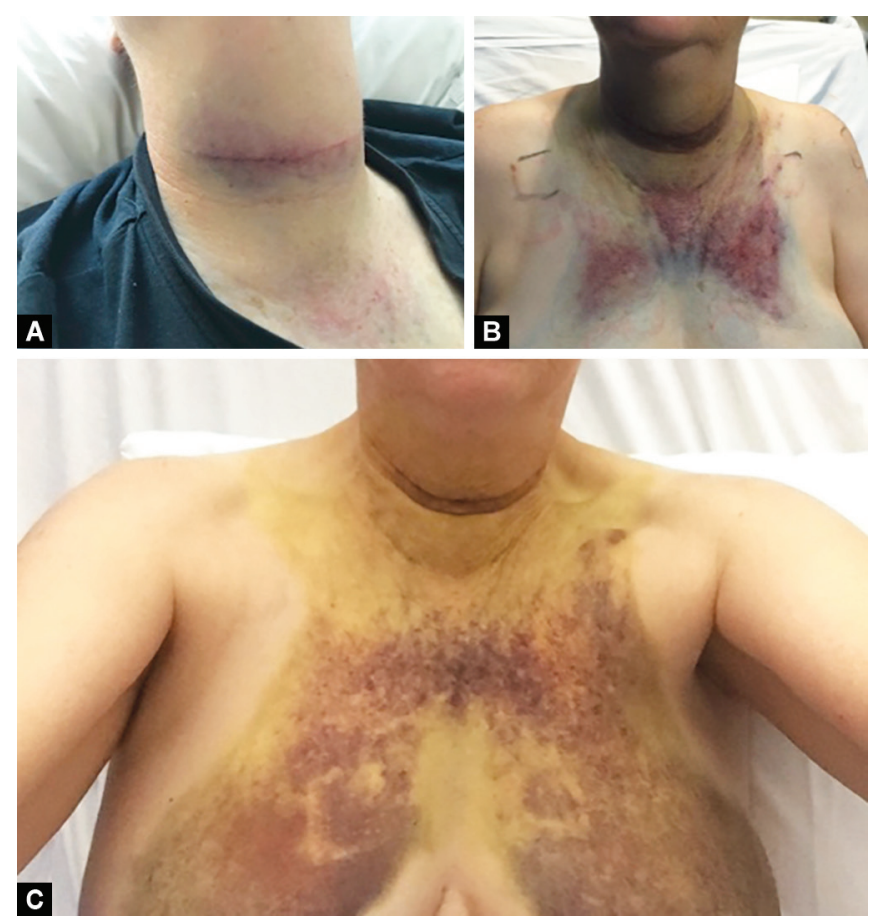

Figs 1 A to C: Neck swelling and ecchymosis at: (A and B) Day 1; (C) Day 5
As the patient was clinically stable, she was discharged with plans to complete investigations as an outpatient. Several diagnoses were considered, including esophageal cancer, which led to a gastrograffin swallow, endoscopic ultrasound (EUS), and positron emission tomography (PET scan). The EUS revealed a mass $5 \mathrm{~cm}$ from the cricopharyngeus, which was biopsied under ultrasound guidance. Cytology revealed epithelioid tumor-like cells of unknown origin. PET scan showed widespread low-grade mediastinal inflammation with no evidence of an FDG avid mass.

\section{Further Imaging}

Following a 3-month interval to allow the hematoma to resolve, a contrast $C T$ scan was repeated (Fig. 3A). There was a residual enhancing $11 \mathrm{~mm}$ nodule, posterior to the trachea, postulated to be a pathological lymph node, parathyroid adenoma, or ectopic thyroid tissue. This finding prompted biochemical investigations, revealing an elevated parathyroid hormone (PTH) of $10.1 \mathrm{pmol} / \mathrm{L}$ (1.6-6.5) elevated corrected calcium of $2.98 \mathrm{mmol} / \mathrm{L}(2.15-2.60)$, and deplete vitamin $\mathrm{D}$ of $41 \mathrm{nmol} / \mathrm{L}$. Referral was made to the endocrine surgery unit, and parathyroid 4DCT was obtained to further evaluate. This study suggested possible multigland disease, with the target lesion enhancement consistent with a prolapsed right superior parathyroid adenoma, but an additional possible left inferior parathyroid adenoma. On surgeon-performed ultrasound, the target lesion was not visible owing to its posterior location. There was a $12 \times 6 \mathrm{~mm}$ ovoid hypoechoic lesion just posterior to the left lower thyroid lobe corresponding to the second possible
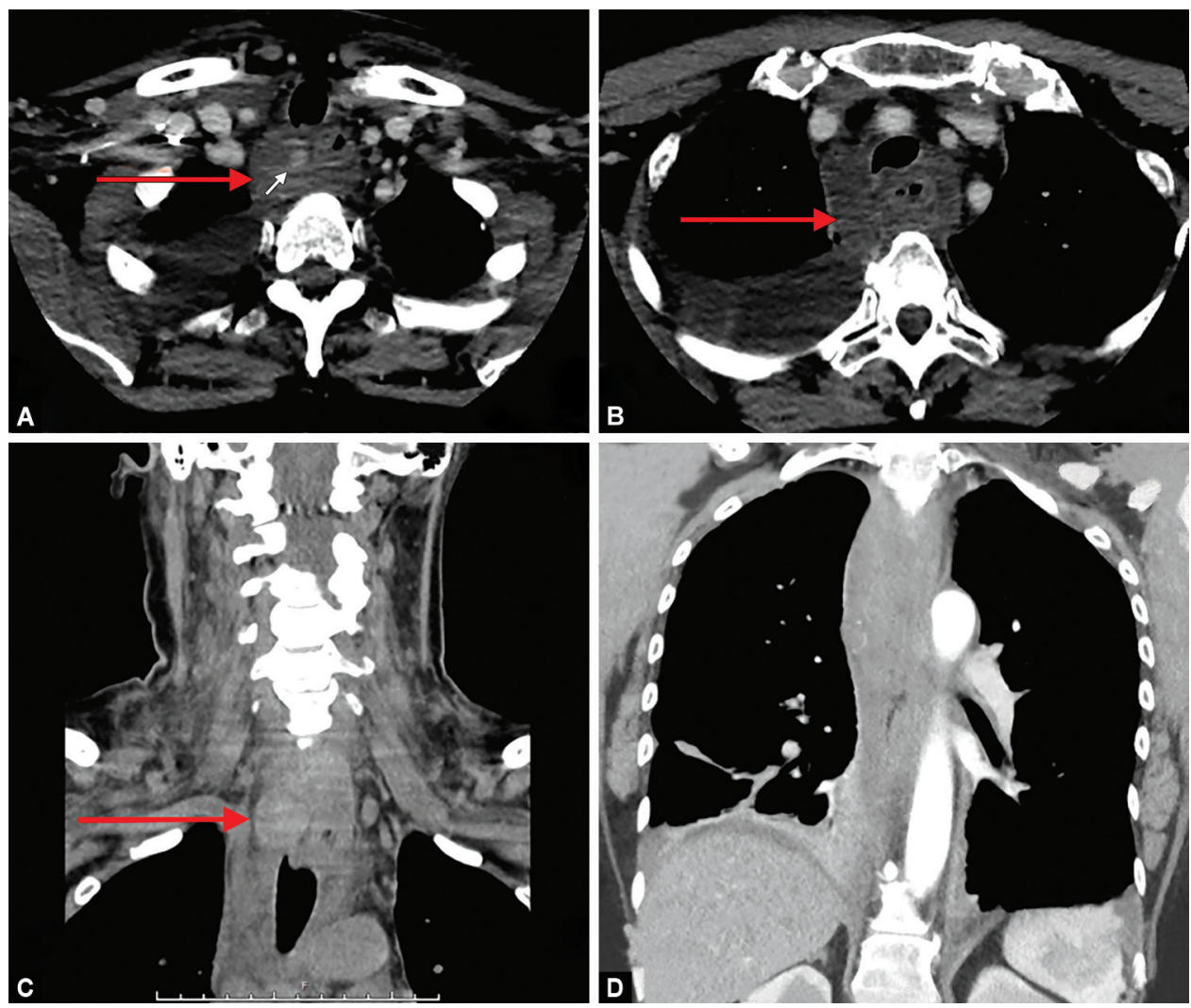

Figs $2 \mathrm{~A}$ to $\mathrm{D}$ : (A and B) Axial; (C and D) Coronal images demonstrating extensive cervical hematoma extending into the thorax 

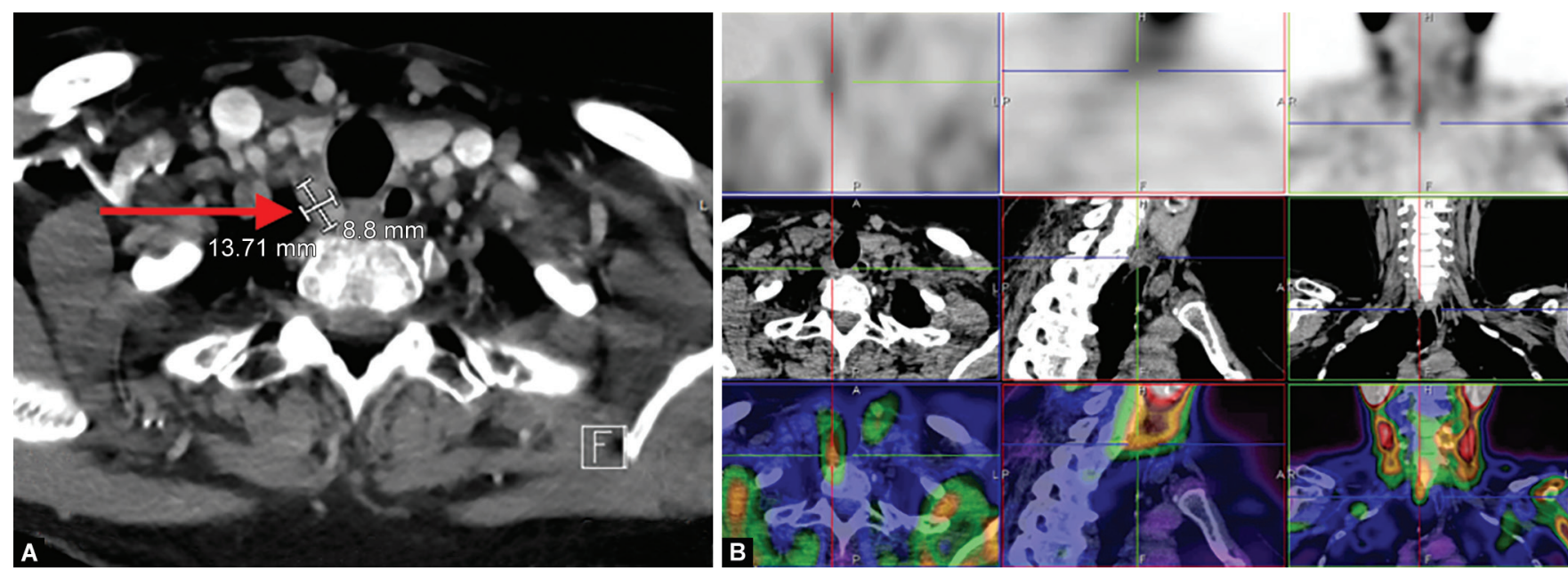

Figs $3 A$ and B: Axial CT image (A) demonstrating resolved cervical hematoma, having a residual nodule with a postcontrast uptake, and sestamibi scan (B) showing an uptake of tracer into a likely parathyroid adenoma

parathyroid adenoma seen on parathyroid 4DCT. However, the presence of a fatty hilum suggested the lesion was a lymph node, rather than a second parathyroid adenoma. Anticipating a difficult operative field after such extensive hemorrhage, and wanting to avoid unnecessary dissection, we then performed a Tc99 parathyroid sestamibi scan (Fig. 3B) to assess uptake in the left-sided lesion. The sestamibi demonstrated a tracer uptake in the prolapsed right superior parathyroid adenoma, but none in the soft tissue nodule adjacent to the left inferior pole, suggesting it was indeed a lymph node. Hence, a decision was made to proceed with a minimally invasive parathyroidectomy.

\section{Surgical Procedure}

Anticipating a difficult procedure, intraoperative nerve monitoring (IONM) was used, which is not our routine practice. A right lateral $3 \mathrm{~cm}$ transverse skin-crease incision was made, and the perithyroidal space was entered between the medial border of the sternomastoid and the lateral border of the strap muscles. Dissection in the central neck revealed firm, fused, opacified tissue planes with residual petechial hemorrhage. A prolapsed right upper parathyroid adenoma adherent to the esophagus, the prevertebral fascia, and the posterior aspect of the recurrent laryngeal nerve was identified (Fig. 4A), and was carefully dissected away from the nerve without injury. No excision of thyroid tissue was necessary, and no contralateral exploration was performed. Pathological examination of the resected parathyroid gland revealed a $813 \mathrm{mg}$ atypical parathyroid adenoma, with minimal fat content and thick fibrous bands. Hemosiderin was evident within the gland (Fig. 4B).

\section{Discussion}

A spontaneous rupture of a bleeding parathyroid gland is an unusual occurrence, first reported by Capps. ${ }^{3}$ In Capps' historical case, the diagnosis of a cervical hematoma from a hemorrhagic parathyroid adenoma was identified only on postmortem examination after the patient died suddenly by suffocation, exhibiting the potentially fatal nature of this condition. Since then, approximately 30 cases have been described in the literature. ${ }^{1-36}$ In almost all cases, blood tests reveal hypercalcemia and hyperparathyroidism. CT, USS, and parathyroid scintigraphy tend to be used in the workup, and definitive surgical management is usually successful (Table 1).

Review of the literature shows that our presented case of parathyroid hemorrhage is similar to other case reports, with patients of a similar demographic presenting with symptoms of hoarseness, dysphagia, cervical swelling, and ecchymosis. Dysphagia (64\%) has been described as the most commonly occurring symptom, followed by cervicothoracic ecchymosis (63\%) and palpable cervical mass (59\%). ${ }^{36}$ As in our case, the swelling and ecchymosis presents $24-48$ hours following the onset of neck discomfort, dysphagia, dyspnea, or hoarseness. The hemorrhage may be intracapsular or extracapsular, dissecting into cervical tissues, often extending into the mediastinum, ${ }^{31}$ for which the requirement of thoracotomy has been described. ${ }^{35}$

The physiopathological mechanisms behind such nontraumatic bleeding from the parathyroid gland are unknown. It has been suggested that this may be due to an imbalance between cellular hyperplasia and blood supply, hence rendering the adenomas susceptible to necrosis and bleeding.,12,33 In the majority of described cases, the pathology of the parathyroid gland was adenoma, and in some cases, it was hyperplasia. Phagocytosis of hemosiderin by macrophages was evident, suggesting hemorrhage from a parathyroid adenoma. ${ }^{28}$

Although surgical management is successful, the optimum timing for surgery and surgical approach is unclear. Van de Broek et al. ${ }^{33}$ describe a case of a 79 -year-old female on oral anticoagulants, who presented with dyspnea amongst other symptoms (Table 1) requiring elective intubation to control the airway. Laryngoscopy and bronchoscopy revealed compression of both the trachea and esophagus with a subglottic stenosis of the trachea. Imaging with SPECT CT and MRI revealed a $200 \mathrm{~mm}$ haematoma from the second cervical vertebra into the posterior mediastinum to the level of the seventh thoracic vertebra. A conservative approach to management was chosen, with reversal of anticoagulation and calcimimetic drug therapy, leading to successful extubation and normalized blood calcium and PTH levels, with a suspicion of autoparathyroidectomy. However, four months later, there was biochemical evidence of recurrent primary hyperparathyroidism, 


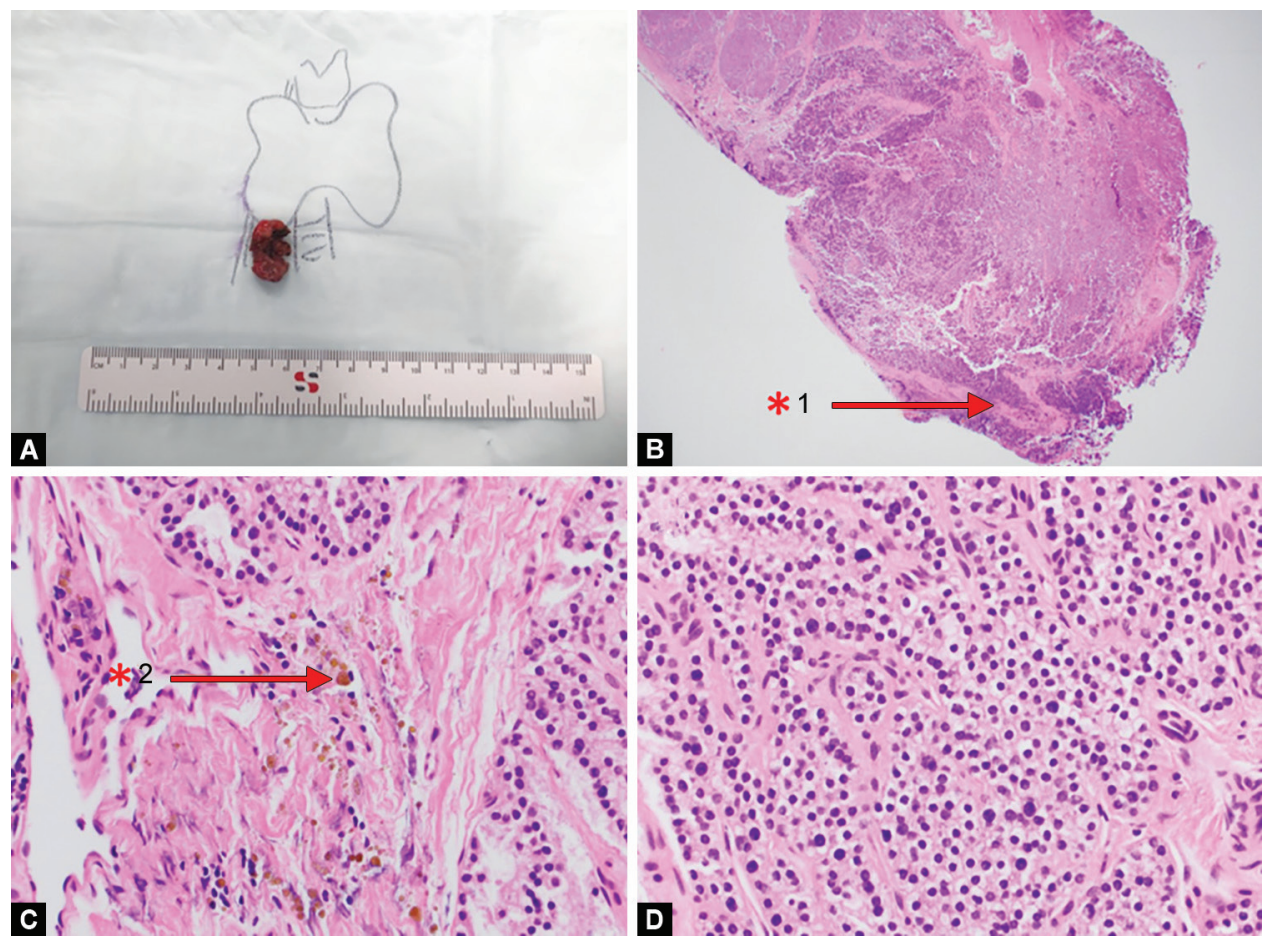

Figs 4A to D: Schematic of perioperative findings that demonstrate a large prolapsed right upper parathyroid adenoma. Histopathological images (B to D) show an abnormal parathyroid gland, with bland cytology and minimal fat content, thick fibrous bands $\left({ }^{*} 1\right)$ and hemosiderin deposition $\left({ }^{*} 2\right)$

and surgery was performed. Owing to difficulty in identification of the adenoma and because of adhesions, a resection of the right lower thyroid lobe was performed, leading to successful restoration of normal calcium metabolism. In contrast, MeranteBoschin et al. ${ }^{1}$ describe a two-stage presentation where vague symptoms prompting outpatient investigation were followed by an emergency admission with massive bleeding and severe respiratory distress requiring emergency hematoma evacuation and en-bloc right thyroid lobectomy.

Owing to the potential risk of a second massive bleed after a less-severe sentinel episode, Ulrich et al. suggest a period of about 1 month observation only. They present a case of a patient discharged following a 3-day admission, in the hope of self-infarction of the pathological gland (autoparathyroidectomy). Eventual elective surgical exploration of the neck 3 months later was difficult, revealing a fixed mass at the inferoposterior pole of the left thyroid gland which was attached to the inferior thyroid artery and left recurrent laryngeal nerve (RLN) posteriorly. This mass was dissected from an area of surrounding hemorrhagic change, which included blood clot and fibrinous material.

Early surgery has been reported to be associated with inability to excise the implicated mass, death from cardiac failure, recurrent laryngeal nerve palsy, and concurrent partial thyroidectomy. Chaffanjon et al. ${ }^{36}$ describe a series of four patients presenting with hemorrhagic parathyroids (of 692 patients undergoing parathyroid surgery) operated at 3 days, 1 month, 3 months, and 4 months, following the initial bleeding event. They conclude that initial conservative management should be employed where possible, with a minimum of 3 months between presentation and surgery. In our presented case, a surgery was performed 3 months after the acute presentation, which, despite the challenging dissection required, resulted in successful treatment with a minimally invasive approach, and voice preservation.

\section{Conclusion}

In the event of a bleeding parathyroid adenoma, anecdotal evidence, and first principles suggest initial conservative treatment should be employed, provided the airway is not threatened, to allow time for biochemical diagnosis and, once the hematoma as resolved, accurate localization of the abnormal gland. Although a second episode of bleeding may occur, there is a likely benefit of delaying surgery to minimize the risks to the recurrent laryngeal nerve. Despite not being a routine user, we elected to use IONM, and found it to be helpful during this particular procedure. Despite an appropriate delay, challenging surgery should be anticipated, including fused tissue planes, fibrosis, and hemosiderin, and should be performed in experienced hands.

\section{Clinical Significance}

A clinical triad of acute neck swelling, hypercalcemia, and neck and/or chest ecchymosis should evoke the potential diagnosis of ruptured parathyroid adenoma. ${ }^{29}$ Careful workup and surgical planning is necessary to establish the diagnosis, and initiate management at an appropriate time, with the appropriate expertise.

\section{Paper Presentation}

Paper was presented at the Asian Society of Endocrine Surgeons meeting, New Delhi, March 2018. 
Table 1: Cases of spontaneous rupture of a parathyroid gland within the last decade, describing the burden of radiological investigations and surgical procedure

\begin{tabular}{|c|c|c|c|}
\hline Author (year) & Clinical features & $\begin{array}{l}\text { Investigations employed } \\
\text { (number) }\end{array}$ & Surgery performed \\
\hline \multirow[t]{5}{*}{$\begin{array}{l}\text { Shim et al. } \\
\text { (March 2008) }\end{array}$} & $44 \mathrm{~F}$ & $\begin{array}{l}\mathrm{CT} \text { ( } \mathrm{x} 2 \text { - second following } \\
\text { aspiration of hematoma) }\end{array}$ & \multirow{5}{*}{$\begin{array}{l}\text { Neck exploration (within } 1 \text { month) } \\
\text { brown-colored cystic mass in the right } \\
\text { tracheoesophageal groove }\end{array}$} \\
\hline & Painful swelling of the anterior neck & Scintigraphy & \\
\hline & Hoarseness & & \\
\hline & Headache on the right occipital area & & \\
\hline & $\begin{array}{l}\text { Pain radiating to her right shoulder and } \\
\text { forearm }\end{array}$ & & \\
\hline \multirow[t]{4}{*}{$\begin{array}{l}\text { Merante-Boschin et al. }{ }^{1} \\
\text { (May 2009) }\end{array}$} & $56 \mathrm{~F}$ & USS (2) & $\begin{array}{l}\text { Severe respiratory distress led to } \\
\text { emergency surgery }\end{array}$ \\
\hline & $\begin{array}{l}\text { Right-sided neck mass and swelling } \\
\text { (two-stage) }\end{array}$ & $\mathrm{CT}$ & · Hematoma evacuation \\
\hline & & & - Parathyroidectomy \\
\hline & & & - "En bloc" right thyroid lobectomy \\
\hline \multirow[t]{4}{*}{$\begin{array}{l}\text { Ulrich et al. }{ }^{32} \\
\text { (May 2015) }\end{array}$} & $54 \mathrm{~F}$ & $\mathrm{CT}(2)$ & $\begin{array}{l}\text { Elective neck exploration at approximately } \\
3 \text { months }\end{array}$ \\
\hline & Left ear-ache & Parathyroid scintigraphy & $\begin{array}{l}\text { Attached to the inferior thyroid artery } \\
\text { and left recurrent laryngeal nerve (RLN) } \\
\text { posteriorly. }\end{array}$ \\
\hline & $\begin{array}{l}\text { Sudden onset rasping Sensation in } \\
\text { throat }\end{array}$ & USS & $\begin{array}{l}\text { Fused planed with blood clot and fibrin } \\
\text { deposition }\end{array}$ \\
\hline & Swelling and pain over left neck & & \\
\hline \multirow{7}{*}{$\begin{array}{l}\text { Van den Broek et al. }{ }^{33} \\
\text { (March 2015) }\end{array}$} & $79 \mathrm{~F}$, on anticoagulants & USS & Intubation due to stridor. \\
\hline & Globus sensation & Scintigraphy & $\begin{array}{l}\text { Conservative treatment planned initially, } \\
\text { which failed }\end{array}$ \\
\hline & Malaise & SPECT scan & $\begin{array}{l}\text { Elective resection of the right lower thyroid } \\
\text { lobe after } 4+\text { months. }\end{array}$ \\
\hline & Progressive pain & MRI & \\
\hline & Mild dyspnea & & \\
\hline & Tender neck, but no obvious swelling & & \\
\hline & $\begin{array}{l}\text { Laryngoscopy and bronchoscopy- } \\
\text { compression of trachea and esophagus }\end{array}$ & & \\
\hline \multirow{4}{*}{$\begin{array}{l}\text { Shinomia et al. }{ }^{28} \\
\text { (November 2015) }\end{array}$} & $76 \mathrm{~F}, 62 \mathrm{M}$ & $\mathrm{CT}$ & Elective (7 months) \\
\hline & Pharyngeal discomfort & Scintigraphy & - Overlying left recurrent laryngeal nerve \\
\hline & Extensive ecchymosis & & - Parathyroidectomy \\
\hline & $\begin{array}{l}\text { Endoscopic evidence of submucosal } \\
\text { laryngeal, nasopharyngeal and } \\
\text { hypopharyngeal hemorrhage. }\end{array}$ & & $\begin{array}{l}\text { - Adhered to surrounding tissues } \\
\text { including the esophageal muscle and } \\
\text { recurrent nerve. }\end{array}$ \\
\hline \multirow{3}{*}{$\begin{array}{l}\text { Zhao et al. }{ }^{34} \\
\text { (November 2015) }\end{array}$} & $52 \mathrm{~F}$ & $\mathrm{CT}(\mathrm{x} 2)$ & \multirow{3}{*}{$\begin{array}{l}\text { Early parathyroidectomy (modality not } \\
\text { defined), within } 4 \text { weeks, mass adherent to } \\
\text { surrounding tissue }\end{array}$} \\
\hline & $\begin{array}{l}\text { Sudden onset neck pain and swelling } \\
\text { Diffuse neck swelling }\end{array}$ & USS & \\
\hline & Ecchymosis & & \\
\hline
\end{tabular}

\section{References}

1. Merante-Boschin I, Fassan M, et al. Neck emergency due to parathyroid adenoma bleeding: a case report. J Med Case Rep 2009;3: 7404. DOI: 10.1186/1752-1947-3-7404.

2. Yoshimura $\mathrm{N}$, Mukaida $\mathrm{H}$, et al. A case of an acute cervicomediastinal hematoma secondary to the spontaneous rupture of a parathyroid adenoma. Ann Thorac Cardiovasc Surg 2014;20(Suppl):816-820. DOI: 10.5761/atcs.cr.12.02060.

3. Capps R. Multiple parathyroid tumors with massive mediastinal and subcutaneous hemorrhage: a case report. Am J Med Sci 1934 188.
4. Akimoto T, Saito O, et al. A case of thoracic hemorrhage due to ectopic parathyroid hyperplasia with chronic renal failure. Am J Kidney Dis 2005 Jun;45(6):e109-e114. DOI: 10.1053/j.ajkd.2005.03.004.

5. Alame A, Solovei G, et al. Parathyroid adenoma revealed by extracapsular cervico-mediastinal hemorrhage. Presse Med 1990 Apr;19(17):817.

6. Amano Y, Fukuda I, et al. Hemorrhage from spontaneous rupture of a parathyroid adenoma: A case report. Ear Nose Throat J 1993 Dec;72(12):794-799. DOI: 10.1177/014556139307201208.

7. Berry BE, Carpenter PC, et al. Mediastinal hemorrhage from parathyroid adenoma simulating dissecting aneurysm. Arch Surg 1974 May;108(5):740-741. DOI: 10.1001/archsurg.1974.01350290102019. 
8. Devezè A, Sebag F, et al. Parathyroid adenoma disclosed by a massive cervical hematoma. Otolaryngol Head Neck Surg 2006 Apr;134(4):710-712. DOI: 10.1016/j.otohns.2005.03.075.

9. Govindaraj S, Wasserman J, et al. Parathyroid adenoma autoinfarction: A report of a case. Head Neck 2003 Aug;25(8):695-699. DOI: 10.1002/ hed.10244.

10. Hellier WP, McCombe A. Extracapsular haemorrhage from a parathyroid adenoma presenting as a massive cervical haematoma. J Laryngol Otol 1997 Jun;111(6):585-587. DOI: 10.1017/ S0022215100137995.

11. Hotes LS, Barzilay J, et al. Spontaneous hematoma of a parathyroid adenoma. Am J Med Sci 1989 May;297(5):331-333. DOI: 10.1097/00000441-198905000-00012.

12. Howard J, Follis RH, et al. Hyperparathyroidism. Case report illustrating spontaneous remission due to necrosis of adenoma, and a study of the incidence of necrosis in parathyroid adenomas. J Clin Endocrinol 1953 Aug;13(8):997-1008. DOI: 10.1210/jcem-13-8-997.

13. Jordan FT, Harness JK, et al. Spontaneous cervical hematoma: a rare manifestation of parathyroid adenoma. Surgery 1981 Jun;89(6): 697-700.

14. Jougon J, Zennaro O. Acute cervico-mediastinal hematoma of parathyroid origin. Ann Chir 1994;48(9):867-899.

15. Kihara $\mathrm{M}$, Yokomise $\mathrm{H}$, et al. Spontaneous rupture of a parathyroid adenoma presenting as a massive cervical hemorrhage: report of a case. Surg Today 2001;31(3):222-224. DOI: 10.1007/ s005950170172.

16. Korkis AM, Miskovitz PF. Acute pharyngoesophageal dysphagia secondary to spontaneous hemorrhage of a parathyroid adenoma. Dysphagia 1993;8(1):7-10. DOI: 10.1007/BF01351471.

17. Kozlow W, Demeure MJ, et al. Acute extracapsular parathyroid hemorrhage: case report and review of the literature. Endocr Pract 2001 Jan-Feb;7(1):32-36. DOI: 10.4158/EP.7.1.32.

18. Ku $\mathrm{P}$, Scott $\mathrm{P}$, et al. Spontaneous retropharingeal haematoma in a parathyroid adenoma. Aust N Z J Surg 1998;68(8):619-621. DOI: 10.1111/j.1445-2197.1998.tb02117.x.

19. Mantion G, Le Guillouzic Y, et al. Spontaneous cervical hematoma secondary to parathyroid adenoma. Presse Med 1990 Jan;19(25):1197.

20. Massard JL, Peix JL, et al. Cervico-mediastinal hemorrhage revealing parathyroid adenoma. Presse Med 1989 Oct;18(31):1524-1525.

21. Maweja S, Sebag F, et al. Spontaneous cervical haematoma due to extracapsular haemorrhage of a parathyroid adenoma: a report of 2 cases. Ann Chir 2003 Oct;128(8):561-562. DOI: 10.1016/S00033944(03)00184-6.

22. Menegaux F, Boutin Z, et al. Large cervical hematoma of parathyroid origin. Presse Med 1997 Dec;26(40):1969.
23. Nakajima J, Takamoto S, et al. Parathyroid adenoma manifested by mediastinal hemorrhage: report of a case. Surg Today 2002;32(9): 809-811. DOI: 10.1007/s005950200155.

24. Osorio Silla I, Lorente $L$, et al. Spontaneous neck hematoma due to rupture of parathyroid adenoma: report of 3 cases and literature review. Endocrinol Nutr 2014 Jan;61(1):e5-e6. DOI: 10.1016/ j.endonu.2013.04.014.

25. Roma J, Carrio J, et al. Spontaneous parathyroid hemorrhage in a hemodialysis patient. Nephron 1985;39(1):66-67. DOI: 10.1159/000183342.

26. Santos $\mathrm{GH}$, Tseng $\mathrm{CL}$, et al. Ruptured intrathoracic parathyroid adenoma. Chest 1975;68(6):844-846. DOI: 10.1378/chest. 68.6.844

27. Shim WS, Kim IK, et al. Non-functional parathyroid adenoma presenting as a massive cervical hematoma: a case report. Clin Exp Otorhinolaryngol 2008;1(1):46-48. DOI: 10.3342/ceo.2008.1.1.46.

28. Shinomiya $\mathrm{H}$, Otsuki $\mathrm{N}$, et al. Parathyroid adenoma causing spontaneous cervical hematoma: two case reports. BMC Res Notes 2015;8:726. DOI: 10.1186/s13104-015-1611-0.

29. Simcic KJ, McDermott MT, et al. Massive extracapsular hemorrhage from a parathyroid cyst. Arch Surg 1989;124(11):1347-1350. DOI: 10.1001/archsurg.1989.01410110109023.

30. Taniguchi I, Maeda T, et al. Spontaneous retropharyngeal hematoma of a parathyroid cyst: report of a case. Surg Today 2003;33(5):354-357. DOI: $10.1007 / \mathrm{s} 005950300080$.

31. Tonerini $M$, Orsitto $E$, et al. Cervical and mediastinal hematoma: presentation of an asymptomatic cervical parathyroid adenoma: case report and literature review. Emergency Radiol 2004;10(4):213-215. DOI: $10.1007 / \mathrm{s} 10140-003-0317-0$.

32. Ulrich L, Knee G, et al. Spontaneous cervical haemorrhage of a parathyroid adenoma. Endocrinol Diabetes Metab Case Rep 2015;2015:150034. DOI: 10.1530/EDM-15-0034.

33. van den Broek JJ, Poelman MM, et al. Extensive cervicomediastinal hematoma due to spontaneous hemorrhage of a parathyroid adenoma: a case report. J Surg Case Rep 2015;2015(5):rjv039. DOI: $10.1093 / \mathrm{jscr} / \mathrm{rjv} 039$.

34. Zhao C, Wang $X$, et al. Parathyroid adenoma causing a spontaneous cervical and mediastinal massive hematoma. Int J Clin Exp Med 2015;8(11):21826-21829.

35. Burgueser MV, Diller A, et al. Spontaneous mediastinal hematoma as initial presentation of cystic adenoma of ectopic parathyroid. Rev Fac Cien Med Univ Nac Cor 2011;68(4):164-168.

36. Chaffanjon PC, Chavanis N, et al. Extracapsular hematoma of the parathyroid glands. World J Surg 2003;27(1):14-17. DOI: 10.1007/ s00268-002-6429-y. 